\title{
IMPLEMENTATION OF A HANDS-ON WORKSHOP TO TEACH COMPETENCIES IN 3D PRINTING
}

\author{
Joachim GUENTHER \\ Munich University of Applied Sciences, Germany
}

\begin{abstract}
Often, new technologies like additive manufacturing and digital technologies are taught at university primarily theoretically with the help of displaying images and short videos. Students regularly miss the practical application of digital technologies as well as the experience and the possibility to develop creative new ideas with these technologies. Obstacles for applying practical usage of digital technologies for students are for many universities the lack of the required equipment in large amounts as well as of technical knowledge. This paper describes how Munich University of Applied Sciences (MUAS) has started to integrate 3D printing into hands-on-activities for students to provide them with these highly relevant skills and competences. Students experience how their creative ideas become immediately visible and haptic due to the new approach of additive manufacturing and 3D printing. This provides an excellent basis for follow-up study projects in various modules. The approach is based on a one-day workshop in which the students work in small teams and solve several problems in mini-projects, called assignments. Through the haptic, collaborative and self-directed learning concept, students understand and reflect the functionalities and limitation of 3D printing in detail. The lecturer acts primarily as a coach during these workshops. The overall feedback from students is very positive and the first innovative use cases in following semesters will be described.

The concept presented below was implemented with some 70 voluntary participants at the Faculty of Industrial Engineering and Management. It is planned to firmly anchor the developed workshops in the curriculum of existing courses (see section 7).
\end{abstract}

Keywords: Engineering and management, additive manufacturing, learning lab, digital technology

\section{INTRODUCTIONS}

Globalization and digitization affect not only the business world, but also significantly university teaching. Besides competencies in the theory of new methods of manufacturing (focusing on explaining the method) students need to work with these technologies hands-on to experience the benefits and limitations. The further described concept of a workshop in which students have the possibility to gain experience on their own consists of a didactic concept which was initialized in a one-day workshop. Furthermore, the necessary resources for the workshop, the structure and the results of several executions are presented. Finally, an outlook on other digital technologies workshops will be given.

What is new about our approach?

The hands-on workshop for 3D printing can be used flexibly for

- $\quad$ first-year students and students in advanced semesters

- $\quad$ students of different fields of study - engineering and non-engineering

The description of the workshop and the assignment are available and downloadable for interested lecturers (see section 8).

\section{DIDACTIC CONCEPTS}

Our idea of teaching is based on the conviction that learning is most effective when knowledge is acquired independently, experienced in one's own actions and applied in experiments [1]. This change of perspective from knowledge transfer didactics to didactics of self-directed acquisition of knowledge and competences leads to didactic demands: from input to infrastructure (design of stimulating learning environments), opening of the subject classification to situation dynamics (learning in situation-typical key situations), from instruction to self-directed learning [2]. The developed workshop learning infrastructure, which is temporarily set up in a seminar room with flexible furnishings and reflective 
walls, is therefore based on a special didactic setting [3]. The assignments allow a playful introduction to 3D printing and are characterized by incomplete tasks. By detailing the solution steps, the degree of difficulty of the assignments increases continuously. After an easy introduction, the complexity increases (e.g. setting up your printing chain from CAD via slicing to 3D printing) and enables a haptic and visual component in the digital world characterized by immaterialization. Students also experience challenges and setbacks during their teamwork. Fast successes motivate the students working collaboratively, whereby among learning strategies as well as time management are individually arranged by the teams. That allows independent control of their own learning pace. The lecturer is on site as a coach.

\section{RESOURCES FOR THE WORKSHOP}

To provide the industrial engineering and management students with practical competencies in 3D printing we developed a one-day workshop, named "Print your own World" (POW). Due to the low investment costs for 3D printers, we purchased eight 3D printers and can perform this workshop with up to 24 students. The students form teams of three (see figure 1) and start from unpacking the 3D printer and finish with designing their own components and printing them at the end of the day. In total the oneday workshop includes ten mini-projects, so-called assignments. Students perform these assignments at their own speed. At the end of each assignment, there is a period of reflection - called retrospective with a short documentation to capture insights and drawbacks. The assignments are also solvable for non-technical students, and the difficulty level increases during the workshop. There is no fixed workshop schedule and it is not a must to finish all assignments during the eight hours of the workshop. For the POW workshop we use Renkforce 100 v2 printers with accessories (USB cable, filament and tools). These 3D printers are easy to use, also for beginners. In addition, each team requires a laptop, which is connected to the printer during the workshop. With the laptop students can also search for necessary information on the Internet. The laptops are also used to design volume models with the CAD system. The printers are robust and work according to the „Fuse Deposition Modelling” process (FDM) [4]. This is the manufacturing process by which a workpiece is built up in thin layers from melted plastic. The working environment requires a room with flexible desks where students can work in their teams, power supplies and Wi-Fi connection. The assignments are printed on paper for the students. There are coloured moderation cards and boards in the room, where notes, results and questions can be posted.

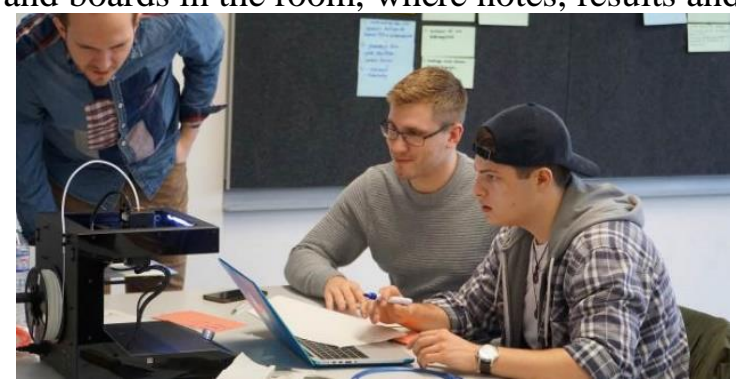

Figure 1. Student team at work

\section{WORKSHOP INSTRUCTION}

It has been found practicable to arrange the student's teams in a way that students who already know each other are not in a team. The teams are set up with the aim of bringing together a range of students, from freshmen to students in their second or third year of studies. As an introduction to the workshop the lecturer explains the self-guided learning approach and how to use the assignments. Furthermore, he/she tells the students where they can pick up the assignments step by step on their own. At the end, he/she explains where the team notes from the "retrospective" are posted. The groups can take breaks when they want. A lunch together with all participants is organized.

\section{STRUCTURE AND CONTENT OF THE ASSIGNMENTS}

The assignments build on each other and are partly incomplete. They are also solvable for non-technical students. Table I shows the assignments and their contents. They have a fixed structure consisting of:

- Learning Objectives

- Required Equipment

- Working Steps

- Hints (to solve problems that may arise during work) 
- Useful internet links for own search

- Retrospective

Table 1. Overview of the assignments used in the workshop

\begin{tabular}{|c|c|c|}
\hline \# & Title & Tasks \\
\hline 1 & Start the engine & $\begin{array}{l}\text { Unbox, assemble and prepare the } 3 \mathrm{D} \\
\text { printer. }\end{array}$ \\
\hline 2 & Your first 3D print & $\begin{array}{l}\text { Understand the printing process and print } \\
\text { the first predefined } 3 \mathrm{D} \text { object. }\end{array}$ \\
\hline 3 & $\begin{array}{l}\text { Transfer a } 2 \mathrm{D} \text { hand-drawn } \\
\text { object into a } 3 \mathrm{D} \text { model }\end{array}$ & $\begin{array}{l}\text { Create a 3D sketch from a technical } \\
\text { drawing. Transfer the sketch into a 3D } \\
\text { model in the CAD system "TinkerCAD". }\end{array}$ \\
\hline 4 & From bytes to atoms & $\begin{array}{l}\text { Open the model in the slicer software. } \\
\text { Prepare the object for printing by setting } \\
\text { printing parameters (the software "Cura" } \\
\text { is used for the slicing process). }\end{array}$ \\
\hline 5 & Setting up the process chain & $\begin{array}{l}\text { Connect the laptop with the printer via } \\
\text { USB. Start work with the process chain } \\
\text { from CAD to slicing and printing (the } \\
\text { software "Repetier-Host" is used for } \\
\text { supervision of the parameters during } \\
\text { printing). }\end{array}$ \\
\hline 6 & Optimizing your prints & $\begin{array}{l}\text { Understand printing parameters and how } \\
\text { they influence the results. Print objects } \\
\text { with different parameters. }\end{array}$ \\
\hline 7 & $\begin{array}{l}\text { 3D model resources on the } \\
\text { web }\end{array}$ & $\begin{array}{l}\text { Find databases of } 3 D \text { models in the web } \\
\text { and choose suitable models for FDM } \\
\text { printing. }\end{array}$ \\
\hline 8 & Generate your own model & $\begin{array}{l}\text { Design own models and print them } \\
\text { (examples see figure } 2 \text { ). }\end{array}$ \\
\hline 9 & $\begin{array}{l}\text { Outlook and possibilities of } \\
\text { Rapid Prototyping }\end{array}$ & $\begin{array}{l}\text { Search for information about other } \\
\text { technologies of 3D Printing (e.g. SLS). } \\
\text { Find out where 3D printers are available at } \\
\text { the university. }\end{array}$ \\
\hline 10 & $\begin{array}{l}\text { Feedback - improving the } \\
\text { POW workshop }\end{array}$ & $\begin{array}{l}\text { Tell us what you liked and what you } \\
\text { disliked about the workshop (in a paper- } \\
\text { based questionnaire). Give feedback for } \\
\text { improvement of the workshop. }\end{array}$ \\
\hline
\end{tabular}

\section{EVALUATION FROM THE PARTICIPANTS}

Up to now the POW workshop was held four times in 2019 and 2020 with 69 participants in total. Since the second workshop we have the participants complete a questionnaire to assess the event from the students' perspective. We received feedback and ideas to improve the workshop from 46 participants. The diagrams in figure 3 represent the number of answers on the $y$-axis referring to the scale on the $x$ axis $(1=$ totally agree $/ 5=$ totally disagree $/$ grade $1=$ very good $/$ grade $5=$ unsatisfying $)$. Students' responses were very positive, and they rated the workshop in average 1.4 or better in all six questions. The questionnaire also contains three open questions at the end.

- What did I like in the workshop?

- What did I not like in the workshop?

- Any comments?

The written answers were clustered and are summarized here: Students documented that they liked the concept of working hands-on on their own, self-responsibly and without time pressure. They emphasized that the opportunity to design and build their own models was one of the highlights of the workshop. Very few critical responses were documented. For some students, for example, the workshop did not offer enough places for students who were interested to participate and for others time was too short. One student wrote in the questionnaire: "the printers are to slow". 


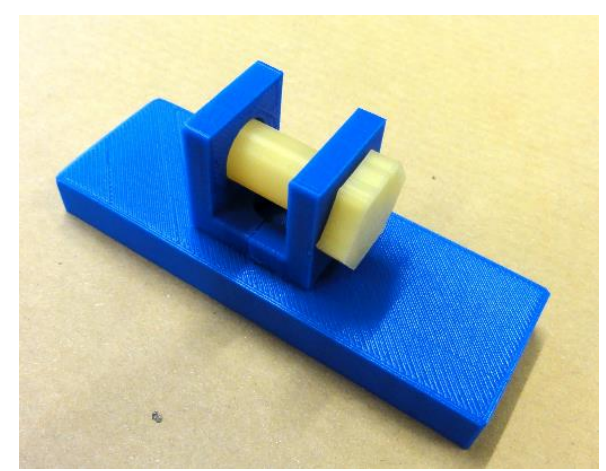

Figure 2. Components designed and printed by a student team (bearing block with bolt)

The ideas for improving the workshop were numerous: The hardware (printers, laptops, cables) should be set up before the workshop in a lab room and should always stay there. The software (Cura, RepetierHost) could be installed on the laptops before the workshops. Both measures would allow more time for the design and printing of their own models. Other suggestions were to provide additional tools (files and drills) to optimize the printed objects. Follow-up workshops with other 3D printing technologies should be organized.
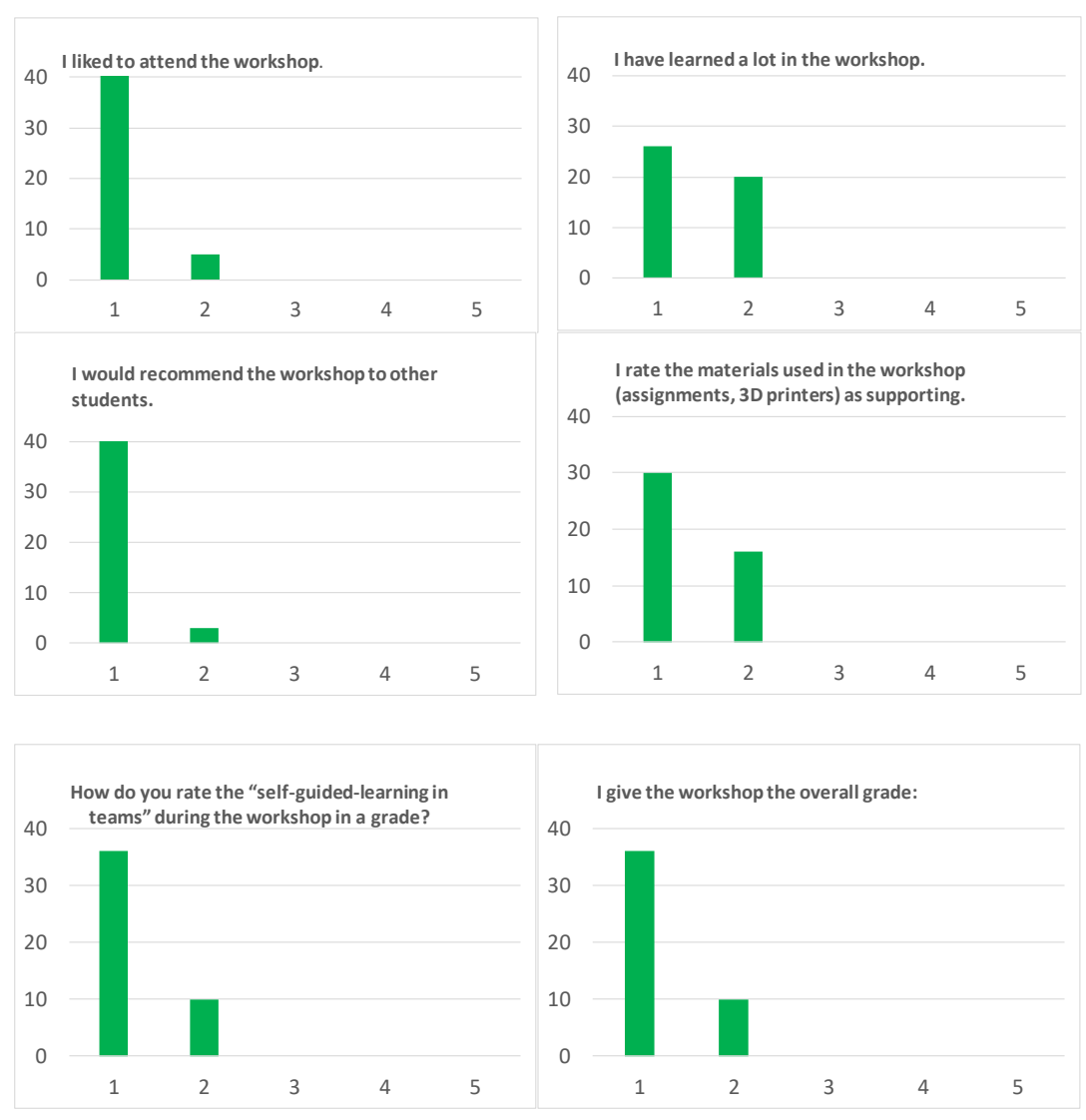

Figure 3. Rating of students in the questionnaire

Two extracts from the questionnaire should show how detailed the answers of the participants were. One student documented: "A positive aspect was the group size. It was not too large, so that everyone in the team could work on the printer and no one had to watch." Another student wrote: "It would be interesting if you had the opportunity to have a selection of different types of 3D printers in the workshop. We could discuss where they are different and which type is the best for which task." 
A very motivating result for the coaches some months after the workshops was that some participants used their acquired 3D printing skills for functional prototypes in their study projects. One example can be seen in figure 4.

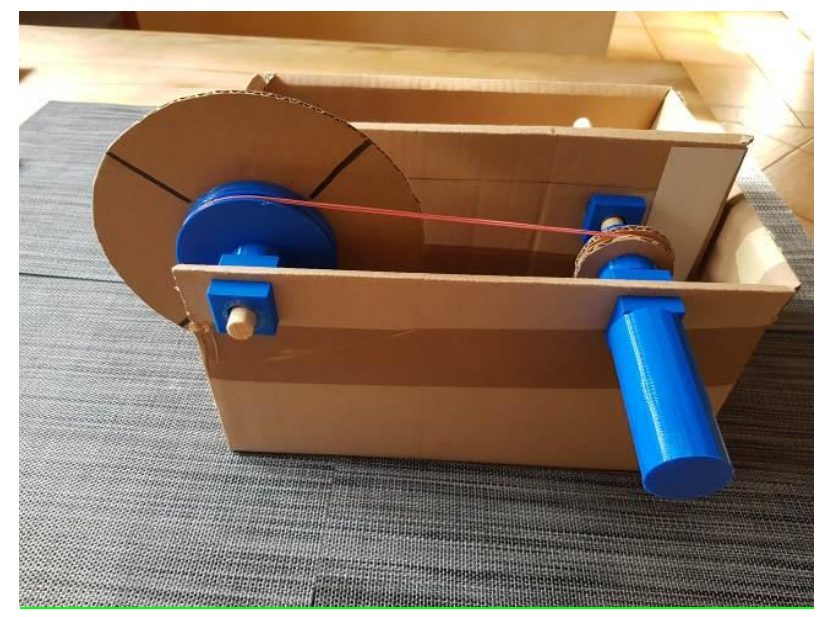

Figure 4. Functional model of a belt transmission with a flywheel and overrunning clutch made of cardboard, wood and 3D printed components (blue)

\section{EXPERIENCES AND CONCLUSIONS}

From the student's point of view, the developed workshop concept with the existing assignments and the small group work is extremely suitable for their own practical experience.

From the teacher's point of view, the greatest effort is the initial preparation of the assignments and the procurement of the necessary material. The time for preparation and follow-up is much less for the following workshops than the first time. Each workshop is also interesting for the teacher, as the teams find new problems and solutions to them. In addition, the teams develop creative ideas for their own models.

From an organizational point of view, the quick physical setup of the mobile learning infrastructure and the high degree of reuse of the assignments in various professional contexts deserve special mention as it makes the workshop setup and execution independent from larger funding and available lab engineers' capacities. It also opens the POW workshop for other departments interested in the technologies of 3D printing.

It was planned to use the workshop POW in the summer semester 2020 in a course for about 50 firstyear students in Technical Drawing. Two workshop days with 25 students each were fixed in the curriculum. Due to the Covid-19 measures, only online teaching was allowed at the Munich University of Applied Sciences. Therefore, the workshop could not be held.

Our future objectives are:

- to include the POW Workshop in courses in different faculties in the curriculum

- to run the workshop with students from different disciplines/faculties

- to systematically record, analyse and compare the feedback from students in engineering and nonengineering courses (e.g. business administration and tourism)

\section{LEARNING LABS FOR DIGITAL TECHNOLOGIES}

The POW workshop described above is embedded in the "Learning Lab for Digital Technologies" (www.114dt.org). The Learning Lab was initiated by Brehm and Günzel [6], both professors at Munich University of Applied Sciences. It offers several one- or two-day workshops which can be added as a plug-and-play building block into a regular course at university. The common basis is the didactic concept of the learning lab based on constructivism and small teams of students who work collaboratively and self-directed on a sequence of assignments. The modular workshop building blocks widen the students' digital competencies in an experimental fashion.

Currently, the learning lab encompasses ten workshops, so-called streams, each based on different digital technologies. Other lecturers benefit from the opportunity to integrate a pre-developed and readyto-use, but also customizable workshop into their lectures. The Learning Lab concept also includes the active creation of a community of lecturers, that develops the Learning Lab content-wise as well as technically and also gives access to numerous students coming in different study areas. 


\section{REFERENCES}

[1] Schüßler, I.: Reflexives Lernen in der Erwachsenenbildung - zwischen Irritation und Kohärenz. In: Bildungsforschung, Jg. 5, Ausgabe 2, 2008, published electronically at http://bildungsforschung.org/ index.php/bildungsforschung/article/view/75 [accessed 2018 May 4th].

[2] Arnold, R.; Erpenbeck, J.: Wissen ist keine Kompetenz. Dialoge zur Kompetenzreifung. Hohengehren: Schneider-Verlag, 2014.

[3] Wong, A. and Partridge, H.: "Making as Learning: Makerspaces in Universities", Australian Academic \& Research Libraries, 47:3, 2016, 143-159. DOI: 10.1080/00048623.2016.1228163

[4] Rayegani, F. and Onwubolu, G.C.: Fused deposition modelling (FDM) process parameter prediction and optimization using group method for data handling (GMDH) and differential evolution (DE), The International Journal of Advanced Manufacturing Technology, July 2014, Volume 73, Issue 1-4, pp 509-519.

[5] Brehm, L.; Guenzel, H.; Hinz, O.; Humpe, A. and Martius H.: Collaborative Learning with COZMO to Teach Programming in SCRATCH and Python. IEEE EDUCON 2019, pp 448-452.

[6] Brehm, L.; Guenzel, H.: Lernwerkstatt Digitale Technologien - Konzeption, Ausprägungen und Erfahrungen. In: Waldherr F.; Walter C. (Hrsg.): Forum der Lehre 2018 - Digitale Akzente setzen. ISSN 1612-4537 / DiNa Sonderausgabe 2018 / page 103 - 108. 